\title{
The Value of Imaging and Composition-Based Biomarkers in Duchenne Muscular Dystrophy Clinical Trials
}

\author{
Stephen M. Chrzanowski ${ }^{1}$ (1) B Basil T. Darras ${ }^{2} \cdot$ Seward B. Rutkove ${ }^{3}$
}

Published online: 26 December 2019

(C) The American Society for Experimental NeuroTherapeutics, Inc. 2019

\begin{abstract}
As the drug development pipeline for Duchenne muscular dystrophy (DMD) rapidly advances, clinical trial outcomes need to be optimized. Effective assessment of disease burden, natural history progression, and response to therapy in clinical trials for Duchenne muscular dystrophy are critical factors for clinical trial success. By choosing optimal biomarkers to better assess therapeutic efficacy, study costs and sample size requirements can be reduced. Currently, functional measures continue to serve as the primary outcome for the majority of DMD clinical trials. Quantitative measures of muscle health, including magnetic resonance imaging and spectroscopy, electrical impedance myography, and ultrasound, sensitively identify diseased muscle, disease progression, and response to a therapeutic intervention. Furthermore, such non-invasive techniques have the potential to identify disease pathology prior to onset of clinical symptoms. Despite robust supportive evidence, non-invasive quantitative techniques are still not frequently utilized in clinical trials for Duchenne muscular dystrophy. Non-invasive quantitative techniques have demonstrated the ability to quantify disease progression and potential response to therapeutic intervention, and should be used as a supplement to current standard functional measures. Such methods have the potential to significantly accelerate the development and approval of therapies for DMD.
\end{abstract}

Keywords Duchenne muscular dystrophy $\cdot$ Clinical trial $\cdot$ Biomarkers $\cdot$ Magnetic resonance imaging $\cdot$ Electrical impedance myography $\cdot$ Ultrasound

\section{Introduction}

A number of potential novel therapies continue to advance in the treatment of Duchenne muscular dystrophy (DMD). Interestingly, therapy development has outpaced biomarker development, creating a paucity of sufficiently sensitive and objective measures of disease progression and response to therapy. As numerous therapeutics continue to advance in clinical trials, biomarker selection remains crucial to assess therapeutic efficacy [1]. Current assessments of clinical efficacy include occurrence of adverse events, individual and

Stephen M. Chrzanowski

stephen.chrzanowski@childrens.harvard.edu

1 Department of Medicine, Boston Children's Hospital, 300 Longwood Ave., Boston, MA 02115, USA

2 Department of Neurology, Boston Children's Hospital, Boston, MA, USA

3 Department of Neurology, Beth Israel Deaconess Medical Center, Boston, MA, USA composite functional tests, various serologic studies, pulmonary and cardiac testing, and a spectrum of questionnaires [1]. A growing work of literature supports utilizing non-invasive quantitative biomarkers rather than traditionally utilized functional outcome measures, because they allow investigators to quantitatively assess longitudinal changes to the state of muscle health. In order to best assess efficacy of clinical trials, outcome measures should be sensitive, safe, repeatable, quantitative, longitudinal, and objective in nature. With support from a growing literature basis, several quantitative biomarkers have been developed to meet such needs. The biomarkers outlined in this review include resonance imaging and spectroscopy (MRI/MRS), electrical impedance myography (EIM), and ultrasound (US).

\section{Methods}

We searched PubMed and Web of Science databases for English language students published between January 2000 and August 2019 for randomized control trials (RCTs), 
meta-analyses, systematic reviews, and observational studies (search terms reported in eAppendix in Supplement). Furthermore, we manually reviewed the references of the listed articles for additional resources. Selected articles were agreed upon by the authors. Queries into ClinicalTrials.gov were also performed, with selection and search criteria as listed: condition or disease: Duchenne muscular dystrophy, study phase: phase 2 and 3 .

\section{Discussion/Observations}

\section{Duchenne Muscular Dystrophy Overview: Pathophysiology, Clinical Presentation, and Diagnosis}

First clinically described by Guillaume-Benjamin Duchenne in 1867 , DMD is characterized by progressive and degenerative proximal to distal muscle weakness, affecting 1 in 5000 to 6250 live male births [2-7]. Etiologically, DMD is caused by out of frame deletions/duplications, nonsense and other mutations to the DMD gene, which normally encodes for the dystrophin protein, which in turn stabilizes the sarcolemmal membrane during muscle contractions $[2,3,8]$. Due to increased susceptibility and vulnerability to contractioninduced injury, repeated cycles of degeneration and repair occur, leading to inflammation, lipid deposition, and eventual fibrosis and muscle non-function [8-10]. The natural progression of muscle damage from unaffected muscle to gross inflammation and edema to fatty replacement and eventual fibrosis of muscle produces increasing alteration in both muscle macro-structure and local physiology. Furthermore, this wellestablished clinical progression of disease leads to early pseudo-hypertrophy of larger but poorly functional muscle, followed by subsequent atrophy and fibrosis of muscle, most notably appreciated in the lower extremity muscle groups. While DMD is classically considered an X-linked recessive disease, the prevalence of de novo mutations has increased to 32 to $46 \%$ as routine anticipatory genetic counseling has decreased the incidence of DMD in families already affected by the disease [11]. Though classically seen to affect skeletal muscle, eventually, all muscles are affected, including respiratory, cardiac, and GI musculature [4, 7, 12-14]. Diagnosis of DMD is presumptively made based on clinical presentation, with confirmation by genetic testing, and by biopsy if genetic tests are non-confirmatory $[6,15]$.

\section{Management, Treatment, and Prognosis}

Until recently, management and treatment of DMD remained limited. The two fundamental realms of treatment remained glucocorticoid disease-modifying therapies and symptomatic management of cardiac, pulmonary, gastrointestinal, endocrine, nutrition, orthopedic, and psychosocial issues [4-6]. Though not curative, glucocorticoid therapy prolongs ambulation, delays functional decline, preserves respiratory function, and reduces the need for scoliosis surgery [16-19]. Though the benefits of glucocorticoids are well defined, much debate remains on the optimal type of steroid, dosing regimen, and time of initiation given glucocorticoid's side effect profile. Prior to supportive and symptomatic management of DMD, life expectancy used to be in the teens, but with better management, individuals now live into their late 20s [20].

In recent years, a number of novel therapeutics have moved through the drug pipeline for the treatment of DMD, in the EU and the USA. In 2014, RNA modifying therapies such as, Translarna (known as Ataluren in the USA) and Eteplirsen were granted conditional marketing authorization by the European Commission and accelerated approval in the USA, respectively [21-24] and in 2016, Eteplirsen was given accelerated approval in the USA [23, 24]. At the time of publication, numerous drugs targeting exon-skipping [23-25], nonsense mutation read through [21,22], utrophin upregulation [26], microdystrophin, and novel anti-inflammatory approaches are currently in or planned for phase $2(n=70)$ and phase $3(n=30)$ trials, highlighting the immediate need for better biomarkers [21-26].

\section{Biomarkers in Clinical Trials for DMD}

With the rapid advancement of numerous potential therapies through the drug development pipeline for DMD, identification and selection of outcome measures and biomarkers are crucial for determining trial design and sample size, as well as the overall success of clinical trials. Assessing therapy efficacy in DMD through traditional functional outcomes is especially difficult for several reasons. First, a child with DMD's functional ability measurement does not follow a linear course. Rather, there is natural growth and functional advancement until about age 5 (the so-called "honeymoon period"), albeit at a slower rate than an unaffected child, at which point the boy's function may continue to improve, plateau, or decline, followed by inevitable decline in almost all patients after age 7 and a precipitous drop in the early teenage years [27]. Secondly, obtaining sufficient numbers to adequately power a well-controlled study for a rare disease such as DMD remains a challenge. Despite being a monogenic disease, DMD has significant phenotypic variation, dependent on causative mutation location, as well as additional diseasemodifying mutations (such as SPP1 and LTBP4), further altering each individual's phenotypic course. Additionally, because of a spectrum of neurologic and psychiatric manifestations of the disease, compliance and ability to repeatedly perform functional assessments may be variable between subjects. Lastly, considering the natural progression of DMD to 
non-ambulatory status, different outcome measures are required between ambulatory and non-ambulatory subjects.

To define the success of clinical trials, outcome measures are utilized to gauge the efficacy of an intervention within a defined cohort. Most simplistically, assessments of a clinical study are either biomarkers or functional measures, either of which can be surrogate measures (Fig. 1). A "biomarker," as a general term, has been defined by the Food and Drug Administration (FDA) as "a characteristic that is objectively measured and evaluated as an indicator of normal biological processes, pathologic processes, or biological response to therapeutic intervention" [28]. More specifically, the FDA recognizes four types or applications of biomarkers: diagnostic, prognostic, predictive, and pharmacodynamic (Table 1.) [29]. Additionally, single biomarkers may serve several roles and measure multiple physiologic processes, depending on the biomarker's mechanism. Functional measures, by definition, measure functional changes in one's health status and describe the impact of treatment on how patients see, feel, and function in their daily lives following an intervention [30]. Importantly, functional measures depend on subjective subject input, requiring compliance and subject interaction. Surrogate markers, in the form of either functional measures or biomarkers, may serve as outcome measures, but not all surrogate markers are necessarily outcome measures. Importantly, surrogate markers identify "a laboratory measurement or physical sign that is used in therapeutic trials as a substitute for a clinically meaningful endpoint that is a direct measure of how a patient feels, functions, or survives, and is expected to predict the effect of the therapy" [30]. The primary difference between biomarkers and functional measures versus surrogate markers is that the former are candidates to serve as surrogate markers, whereas surrogate markers are tested and proven measures of a particular intervention (Fig. 2) [30]. In the rapidly expanding realm of clinical trials for
DMD, the primary surrogate markers used thus far include functional tests, such as the 6-min walk test (6MWT), and composite functional tests (NorthStar Ambulatory Assessment, NSAA; Timed Function Tests, TFTs; Performance of Upper Limb test, PUL test) [31]. Traditional biomarkers that have previously been utilized in clinical trials for DMD include dystrophin expression from muscle biopsy samples, though such invasive tests have fallen out of favor for practical and ethical reasons. Recently, there has been increased interest in non-traditional surrogate biomarkers, such as non-invasive imaging modalities such as MRI/MRS, EIM, and ultrasound.

A summary of the different outcome measures used in phase $2(n=70)$ and phase $3(n=30)$ clinical trials for DMD are shown in Fig. 3. Functional outcome measures assess the clinical manifestations of the disease, either individually (6MWT, 10-m walk/run, four stair climb, and supine to stand test), or as composite tests (NSAA, TFTs, PUL test) [7]. Although the 6MWT was initially designed to assess health in adult chronic obstructive pulmonary disease, it remains the standard measure in the majority of DMD clinical trials. While the ultimate outcome sought is clinical stabilization or improvement, measurable and significant changes in functional tests are often difficult to appreciate given short timescale of most clinical trials. Additionally, appropriately performing the functional tests requires precise measurement with consistent training across evaluators and good effort by the participants. For example, it is well documented that participants perform best during the first and final minutes of the 6MWT, as opposed to the middle $4 \mathrm{~min}$, highlighting its sensitivity to motivation and fatigue [32]. Furthermore, the non-linear trajectory and course of the disease make data comparison and interpretation difficult $[31,33,34]$. Overall, the functional tests, particularly the 6MWT, face many limitations, as highlighted by the FDA's critical assessment of the Eteplirsen trial [23].
Fig. 1 The sarcolemma and dystrophin-associated glycoprotein complex. Dystrophin, highlighted in blue, connects the intracellular actin to the rest of the dystrophin-associated glycoprotein complex

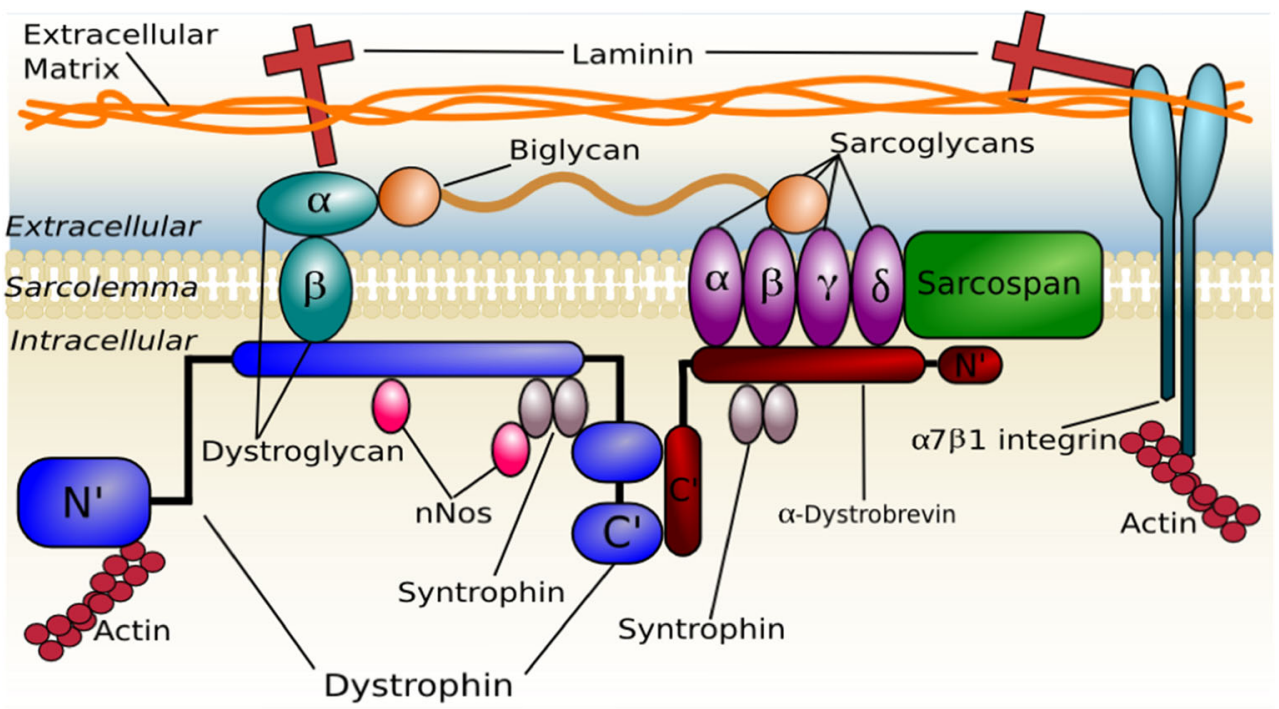


Table 1 Clinical measures and biomarker types recognized by the FDA and relevant examples in DMD. Different types of clinical measures and biomarkers are described with relevant examples to DMD

\begin{tabular}{|c|c|c|}
\hline $\begin{array}{l}\text { Clinical measure } \\
\text { and biomarker type }\end{array}$ & Description & Examples relevant to DMD \\
\hline Diagnostic & $\begin{array}{l}\text { Disease characteristics that categorize people by the presence or absence of } \\
\text { a specific physiologic or pathophysiological state or disease }\end{array}$ & $\begin{array}{l}\text { - Creatine kinase } \\
\text { - Genetic testing of } D M D \text { (Multiplex } \\
\text { ligation-dependent probe amplification or } \\
\text { next-generation sequencing) } \\
\text { - Biopsy with western blotting or dystrophin } \\
\text { immunohistochemistry }\end{array}$ \\
\hline Prognostic & $\begin{array}{l}\text { Baseline characteristic that categorizes patients by degree of risk for } \\
\text { disease occurrence or progression of a specific aspect of disease (i.e. } \\
\text { natural history of disease in the absence of therapeutic intervention) }\end{array}$ & $\begin{array}{l}\text { - Genetic testing of } D M D \\
\text { - Presence of Modifier genes (LTBP4, Anxa6, SPP1) }\end{array}$ \\
\hline Predictive & $\begin{array}{l}\text { Baseline characteristic that categorizes patients by their likelihood of } \\
\text { response to a particular treatment relative to no treatment }\end{array}$ & $\begin{array}{l}\text { - Mutation identification on } D M D \text { to identify specific } \\
\text { mutation for mutation-specific therapy }\end{array}$ \\
\hline $\begin{array}{l}\text { Pharmacodynamic } \\
\text { (activity) }\end{array}$ & $\begin{array}{l}\text { A change demonstrates that a biological response has occurred in a patient } \\
\text { who has received a therapeutic intervention and for which the magnitude } \\
\text { of change is considered pertinent to the response }\end{array}$ & $\begin{array}{l}\text { - Serologic testing (creatine kinase) } \\
\text { - Cardiac function } \\
\text { - Pulmonary function } \\
\text { - Quantitative myography } \\
\text { - Timed function tests } \\
\text { - 6-min walk test } \\
\text { - Manual muscle testing } \\
\text { - Near-infrared spectroscopy }\end{array}$ \\
\hline
\end{tabular}

Biomarkers are independent of patient effort and compliance (Table 2). Most directly, invasive biomarkers such as dystrophin quantification via biopsy are limited because of the traumatic nature of the sample collection. Furthermore, intramuscular heterogeneity of DMD predisposes biopsying to substantial sampling errors [35]. A common screening tool to identify muscle pathology is creatine kinase (CK); however, serum $\mathrm{CK}$ is a ubiquitous marker of muscle injury, is not specific to DMD, and may be elevated in a number of other pathologies and its reduction may not imply improving muscle condition, but rather atrophy as a natural process of the disease. Of recent, there has been great interest in measuring serum microRNA's, having greater specificity for DMD than traditional CK measurements, though this remains a developing field [36].

An optimal biomarker requires minimal patient cooperation, is non-invasive, can be used repeatedly in a longitudinal

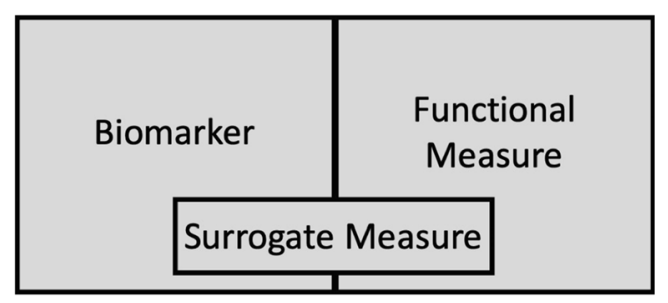

Fig. 2 Relationship between outcome measures, surrogate markers, biomarkers, and functional measures. Surrogate markers can be outcome measures, but not all have been validated by the FDA. Biomarkers and functional measures can be surrogate markers and can serve as outcome measures, but not all biomarkers and functional measures are necessarily validated outcome measures fashion, is adequately sensitive and specific, and is easily translatable from pre-clinical to clinical studies. In this review, we highlight several examples of such non-invasive quantitative biomarkers, specifically magnetic resonance imaging and spectroscopy, electrical impedance myography, and ultrasound (Table 3).

\section{Magnetic Resonance Imaging and Spectroscopy}

MRI and MRS have emerged as potentially powerful, noninvasive quantitative biomarkers for use in clinical trials for DMD [37-41]. Briefly, the MRI transverse relaxation time (MRI- $\mathrm{T}_{2}$ ) represents the overall bulk $\mathrm{T}_{2}$ of a particular region of interest, influenced both by water and lipid components [42]. MRI-T $\mathrm{T}_{2}$ is sensitive to several pathophysiologic features of disease pathology in DMD, including muscle edema, inflammation, and lipid infiltration, and grossly allows for longitudinal monitoring of disease pathology and progression [43]. The first studies that correlated function to MR findings used conventional $\mathrm{T}_{1}$-weighted spin echo imaging, and utilized qualitative assessments to grade the level of disease involvement within muscle [44].

Additionally, assessment of fat fraction has become increasingly utilized to quantify the fat replacement of skeletal muscle, through either chemical shift imaging methods or spectroscopy [45]. As lipid infiltration into muscle is a wellcharacterized pathophysiological process in DMD, identification and quantification of lipid deposition is a strong proxy for 

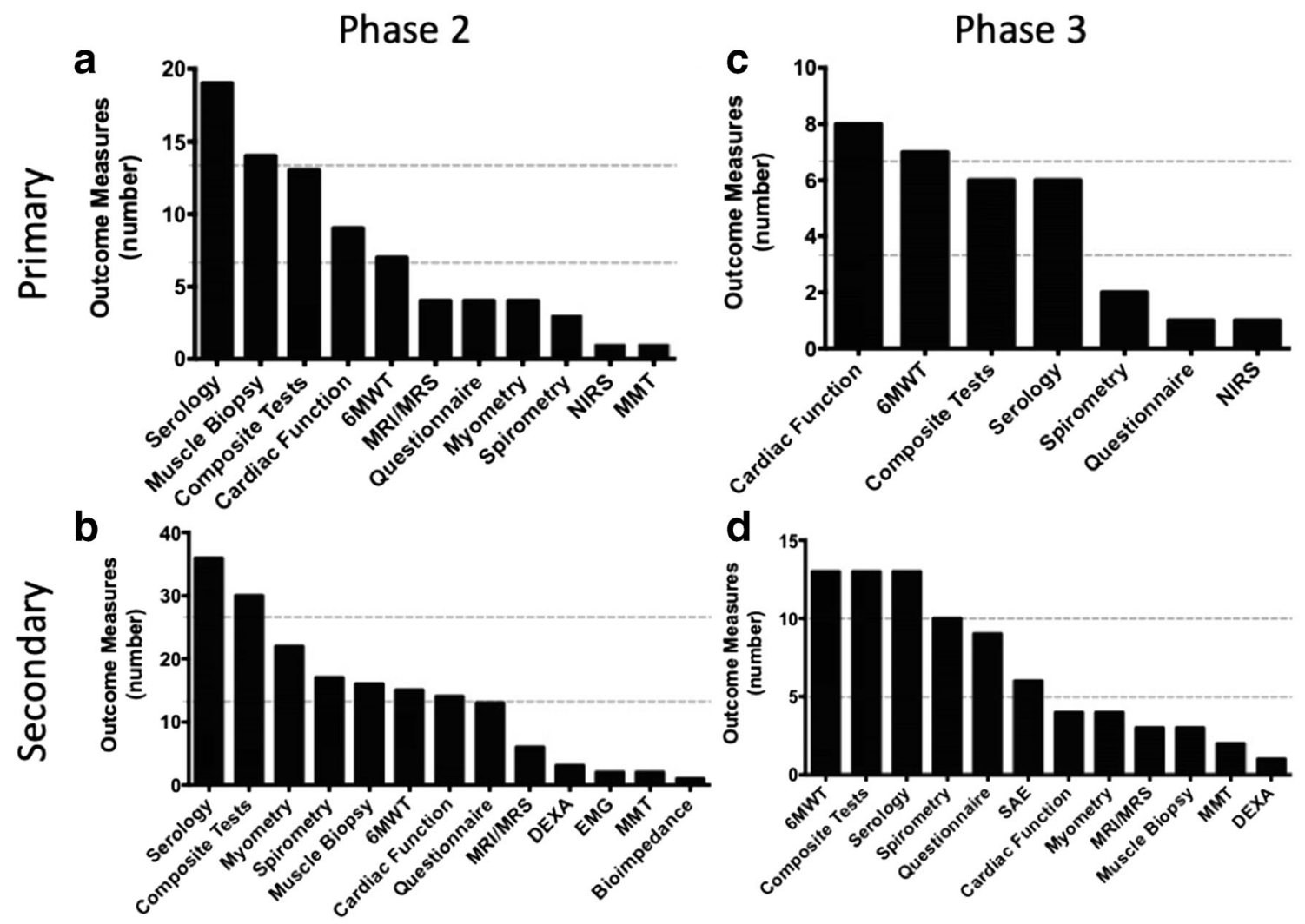

Fig. 3 Primary and secondary outcome measures for phase 2 and 3 clinical trials in DMD. Phase 2 primary $(2 \mathrm{~A})$ and secondary $(2 \mathrm{~B})$ and phase 3 primary (3C) and secondary (3D) outcome measures are shown in descending order by frequency of occurrence. Of note, though adverse outcomes are listed as a primary outcome measure on ClinicalTrials.gov, they are not included in Fig. 2 because they do not assess therapeutic efficacy. Serology: any serologic laboratory test (including chemistries, complete blood counts, creatine kinase, liver function tests); composite

assessment of disease progression. Strong correlations have been demonstrated between the fat fraction of dystrophic muscle to functional tests through both chemical shift and spectroscopic methodologies [46-52] .

Lastly, magnetic resonance spectroscopy, including both ${ }^{1} \mathrm{H}$ and ${ }^{31} \mathrm{P}$ spectroscopy, has commonly been used to provide further insight into biochemical composition and metabolic processes within tissue samples [46, 53-59]. ${ }^{1} \mathrm{H}-\mathrm{MRS}$, through its nature of being independent of lipid infiltration, can indicate muscle damage through acute inflammation and edema within muscle, as well as chronic degenerative changes [57-59]. Broadly, ${ }^{31} \mathrm{P}-\mathrm{MRS}$ assesses energy metabolism through quantification of the phosphocreatine, inorganic phosphate, and ATP, providing information about muscle metabolomics. As lipid replaces functional muscle with progression of DMD, the oxidative capacity of dystrophic muscles decreases, leading to quantifiable metabolic changes that can be measured via ${ }^{31} \mathrm{P}$-MRS $[46,53]$.

Correlation between clinical function and magnetic resonance measures have been well elucidated in a number of cross-sectional studies. Correlations between lower leg tests: PUL, NSAA, MFM, Brooke and Vignos, or a combination of 10-m walk/run + four stair climb + supine to stand tests; Cardiac Function: EKG, echo, or cMRI; 6MWT: 6-min walk test; Questionnaire: PedsQL, Health Utilities Index, Fuctional Outcomes Survey, cognitive testing, PODCI adolescent questioning, or Clinical Global Impression of Improvement questionnaires; NIRS: near-infrared spectroscopy; MMT: manual muscle testing; DEXA: dual-energy x-ray absorptiometry

muscle groups' MRI-T 2 and TFTs $(r=0.23-0.79)$, various MRI measures to PFTs, and upper extremity to PUL scores $(r=0.91)$ have all been demonstrated $[37,50,60]$. Through spectroscopy, significant correlations have been shown between lipid fractions and functional measures $(r=0.52-0.70$, $p<0.001)$ and strength measures $(r=-0.36$ to -0.56 , $p<0.05$ ), a variety of MR measures to upper extremity functional tests (MyoGrip, MyoPinch, MoviPlate, MFM-D3, MFM-total), ${ }^{1} \mathrm{H}_{2} \mathrm{O}-\mathrm{T}_{2}$ and ${ }^{31} \mathrm{P}$ spectroscopy to years since loss of ambulation, fat fraction and MFM $\left(r^{2}=0.93\right)$, and quantitative MR to a multitude of functional measures (10-m walk/run, four stair climb, supine to stand test, and 6MWT) [40, 41, 47, 56, 61].

Perhaps, most importantly, MR has the ability to detect subclinical changes in muscle health, prior to overt symptom onset $[38,62]$. In a study that divided patients into quartiles based on $6 \mathrm{MWT}$ function, increases in MRI- $\mathrm{T}_{2}$ were observed even in subjects whose 6MWT improved, indicating worsening of muscle health despite clinical improvement, anticipating inevitable clinical regression [62]. A separate study demonstrated that a fat fraction level of 
Table 2 Current measures used in DMD clinical trials. A thorough list of functional measures, biologic biomarkers, and non-invasive quantitative measures and how they are utilized in DMD with examples, advantages, and disadvantages of all are provided.

\begin{tabular}{|c|c|c|c|c|c|}
\hline Assessment & Description & Involvement & Examples & Advantages & Disadvantages \\
\hline $\begin{array}{l}\text { Functional } \\
\text { measures }\end{array}$ & Measured tests of gross muscle function & Required & $\begin{array}{l}\text { - } 6 \text { min walk test } \\
\text { - Timed function } \\
\text { tests }(4 \text { stair } \\
\text { climb, supine to } \\
\text { stand, } 10 \text { m walk } \\
\text { run } \\
\text { - North star } \\
\text { ambulatory } \\
\text { assessment } \\
\text { - Performance of } \\
\text { upper limb test } \\
\text { - Quantitative } \\
\text { myometry } \\
\text { - Pulmonary tests }\end{array}$ & $\begin{array}{l}\text { - Assesses overall } \\
\text { state of muscle } \\
\text { health } \\
\text { - Ease of } \\
\text { longitudinal } \\
\text { measurements }\end{array}$ & $\begin{array}{l}\text { - Relies on patient } \\
\text { involvement, motivation, } \\
\text { and compliance } \\
\text { - Changes with children's } \\
\text { natural growth } \\
\text { - Limited sensitivity } \\
\text { (especially after loss of } \\
\text { ambulation) to natural } \\
\text { history and therapeutic } \\
\text { intervention }\end{array}$ \\
\hline $\begin{array}{l}\text { Biologic } \\
\text { biomarkers }\end{array}$ & $\begin{array}{l}\text { Baseline characteristic that categorizes } \\
\text { patients by degree of risk for disease } \\
\text { occurrence or progression of a specific } \\
\text { aspect of disease (i.e., natural history of } \\
\text { disease in the absence of therapeutic } \\
\text { intervention) }\end{array}$ & None & $\begin{array}{l}\text { - Creatine kinase } \\
\text { - Micro-RNAs } \\
\text { - Muscle biopsy } \\
\text { with dystrophin } \\
\text { quantification }\end{array}$ & $\begin{array}{l}\text { - Ease of } \\
\text { longitudinal } \\
\text { measurements in } \\
\text { CK and } \\
\text { micro-RNAs }\end{array}$ & $\begin{array}{l}\text { - Non-focal } \\
\text { - CK has limited specificity for } \\
\text { DMD } \\
\text { - Difficulty in longitudinal } \\
\text { assessments in biopsies } \\
\text { - Difficulty in obtaining } \\
\text { biopsy sample } \\
\text { representative of the whole } \\
\text { state of disease }\end{array}$ \\
\hline $\begin{array}{l}\text { Non-invasive } \\
\text { quantita- } \\
\text { tive } \\
\text { biomarkers }\end{array}$ & $\begin{array}{l}\text { Baseline characteristic that categorizes } \\
\text { patients by their likelihood of response to } \\
\text { a particular treatment relative to no } \\
\text { treatment. }\end{array}$ & Minimal & $\begin{array}{l}\text { - Cardiac function } \\
\text { tests (via echo or } \\
\text { cardiac MR) } \\
\text { - Muscle MR } \\
\text { - Electrical } \\
\text { impedance } \\
\text { myography } \\
\text { - Ultrasound }\end{array}$ & $\begin{array}{l}\text { - Minimal patient } \\
\text { involvement } \\
\text { required } \\
\text { - Quantitative in } \\
\text { nature } \\
\text { - Ease of } \\
\text { longitudinal } \\
\text { assessments } \\
\text { - Sensitive to } \\
\text { changes in } \\
\text { disease state and } \\
\text { therapeutic } \\
\text { intervention } \\
\text { - Easily translatable } \\
\text { from pre-clinical } \\
\text { to clinical stud- } \\
\text { ies }\end{array}$ & $\begin{array}{l}\text { - Expensive } \\
\text { - Timely }\end{array}$ \\
\hline
\end{tabular}

$50 \%$ could anticipate loss of ambulation with a sensitivity of $100 \%$ and specificity of $91 \%$ [47]. Lastly, before and after initiation of corticosteroid therapy in boys with $\mathrm{DMD}$, differences in MRI- $\mathrm{T}_{2}$ and ${ }^{1} \mathrm{H}_{2} \mathrm{O}-\mathrm{T}_{2}$ were noted between steroid naïve and the steroid treatment groups as early as 3 months after the initiation of corticosteroids [38]. MRI studies in DMD reveal that samples sizes fiveto seventeenfold smaller are needed to obtain comparably significant outcomes as compared to motor function measures $[62,63]$.

Despite all of the helpful information generated by MR, it does possess several limitations, most notably cost and accessibility, as devices tend to exist only in large academic centers capable of maintaining such infrastructures. Furthermore, subject compliance is a hindrance as individuals must remain motionless, limiting data collection to older and compliant children that are not affected by claustrophobia, nor have metallic implants. Subtle differences between device manufacturers and software require intra-device calibrations that can limit the multi-site nature of many studies. Inherent to the nature of the technology, MRI- $\mathrm{T}_{2}$ is limited because of multiple contributions to signal (lipid and water) and how lipid introduces a much longer $\mathrm{T}_{2}$ signal than water alone. Furthermore, spectroscopy is limited by the need for a specific region of interest for assessment, limiting global integration in measurements. Nonetheless, MR remains a powerful, quantitative, objective, and longitudinal modality, capable of tracking natural disease progression and response to therapy. 
Table 3 MRI/MRS vs. EIM vs. ultrasound. Non-invasive quantitative measures are compared amongst one another to demonstrate applicability to DMD clinical trials

\begin{tabular}{|c|c|c|c|c|c|}
\hline Biomarker & Mechanism of utility & Measurements & Comments & Advantages & Disadvantages \\
\hline $\begin{array}{l}\text { Magnetic } \\
\text { resonance } \\
\text { imaging and } \\
\text { spectroscopy }\end{array}$ & $\begin{array}{l}\text { Measures intrinsic } \\
\text { biochemical and } \\
\text { biomagnetic } \\
\text { properties of tissue }\end{array}$ & $\begin{array}{l}\mathrm{H}_{2} \mathrm{O}-\mathrm{T}_{2} \text {, fat fraction, anatomical } \\
\text { cross-sectional area, blood oxygen } \\
\text { level dependence, }{ }^{1} \mathrm{H} \text { and }{ }^{31} \mathrm{P} \text { spec- } \\
\text { troscopy }\end{array}$ & $\begin{array}{l}\text { - Sensitive to } \\
\text { disease } \\
\text { progression } \\
\text { - Correlates to } \\
\text { functional } \\
\text { measures } \\
\text { - Sensitive to } \\
\text { therapeutic } \\
\text { intervention } \\
\text { - Can detect } \\
\text { subclinical } \\
\text { changes to } \\
\text { muscle }\end{array}$ & $\begin{array}{l}\text { - Non-invasive } \\
\text { - Quantitative spatial } \\
\text { and spectral } \\
\text { (biochemical) } \\
\text { analysis } \\
\text { - Longitudinal } \\
\text { - Non-ionizing } \\
\text { - Minimal patient } \\
\text { involvement }\end{array}$ & $\begin{array}{l}\text { - Cost } \\
\text { - Long acquisition } \\
\text { times } \\
\text { - Contraindications } \\
\text { (metallic implants, } \\
\text { claustrophobia) } \\
\text { - Not accessible in all } \\
\text { medical centers }\end{array}$ \\
\hline $\begin{array}{l}\text { Electrical } \\
\text { impedance } \\
\text { myography }\end{array}$ & $\begin{array}{l}\text { Measures intrinsic tissue } \\
\text { conductivity and } \\
\text { permittivity of tissue }\end{array}$ & Resistance, reactance, phase & $\begin{array}{l}\text { - Sensitive to } \\
\text { disease } \\
\text { progression } \\
\text { - Correlates with } \\
\text { functional } \\
\text { measures }\end{array}$ & $\begin{array}{l}\text { - Non-invasive } \\
\text { - Quantitative } \\
\text { assessment } \\
\text { - Longitudinal } \\
\text { - Minimal patient } \\
\text { involvement } \\
\text { - Relatively } \\
\text { inexpensive }\end{array}$ & $\begin{array}{l}\text { - Lack of geographic } \\
\text { mapping } \\
\text { - Still developing as a } \\
\text { technology }\end{array}$ \\
\hline Ultrasound & $\begin{array}{l}\text { Measures intrinsic tissue } \\
\text { echointensity }\end{array}$ & Backscatter analysis, grayscale values & $\begin{array}{l}\text { Correlates with } \\
\text { function and } \\
\text { age } \\
\text { Can be used to } \\
\text { identify lipid } \\
\text { or fibrotic } \\
\text { tissue }\end{array}$ & $\begin{array}{l}\text { - Non-invasive } \\
\text { - Easy bedside } \\
\text { accessible } \\
\text { - Inexpensive } \\
\text { - Longitudinal } \\
\text { - Minimal patient } \\
\text { involvement }\end{array}$ & $\begin{array}{l}\text { - Inter-user variability } \\
\text { - Less information } \\
\text { than MRI and EIM } \\
\text { able to be } \\
\text { generated }\end{array}$ \\
\hline
\end{tabular}

\section{Electrical Impedance Myography}

Electrical Impedance Myography (EIM) is another quantitative technology that has been utilized in neuromuscular diseases to longitudinally and non-invasively assess healthy and damaged muscle. Briefly, EIM provides physiological data on the composition and structure of muscle through assessing micro-morphical and intrinsic electrical material properties of tissue, including its conductivity and relative permittivity, and their respective alterations in diseased muscle. These changes are both frequency-dependent and also relate to the directionality of applied current flow (i.e., along or across the muscle fibers). In diseased or damaged muscle, tissue anisotropy, or variation in conductivity and permittivity across myofiber membranes, exists, allowing for low and medium frequency currents to pass more easily than high-frequency currents.

Though a relatively new technology, EIM has been demonstrated to quantitatively assess and monitor disease status, progression, and therapeutic response in several neuromuscular disorders. In DMD, EIM has been used to dichotomously identify individuals with and without DMD as well as demonstrating disease progression [64-66]. Correlation between EIM measures and functional tests (6MWT, NSAA, TFTs, and strength; $r=0.44-0.66)$, NSAA ( $r=0.65, p=0.02)$ and age $(r=0.45, p=0.01)$, and longitudinal differences $(p<0.05)$ have been demonstrated [64-67]. Beyond DMD, EIM has been applied to several other neuromuscular disorders, including spinal muscular atrophy [68, 69], radiculopathy [70], facioscapulohumeral muscular dystrophy [71], and inflammatory myositis [72]. In ALS, EIM has demonstrated the success in longitudinally tracking disease progression, yielding the potential to substantially reduce the number of people needed for a successful clinical trial [73, 74]. Similar to MRI/MRS, the beneficial therapeutic effects of the initiation of corticosteroids was able to be identified with EIM [65]. Similarly, in parallel to DMD trials, EIM has demonstrated the potential to reduce sample size requirements by as much as $50 \%$, as compared to traditional functional outcomes in DMD [73]. A similar finding was appreciated in ALS, in which EIM was able to reduce sample size requirements by greater than a factor of 5 compared to the standard functional questionnaire [75].

In all, EIM's high reproducibility and minimal subject reliance makes it an excellent biomarker to utilize in clinical trials for DMD, though it is not without limitations. Because of the technology's relative youth, less literature exists on the technology, though many studies have demonstrated EIM's 
correlation to functional measures $[64,65,67,73]$. As the technology continues to be refined, further engineering to optimize electrode placement and design will continue to provide further insight into muscle pathology. Overtly, EIM does not generate images based on the nature of the technology, limiting spatial analyses. A unique benefit to EIM is that because of the small and inexpensive nature of EIM devices, it may be possible to monitor disease progression or response to therapy remotely, including at home, allowing for the collection of larger datasets [76]. In all, EIM is a powerful and unique because of its relative ease of use, wide-ranging potential applications, and ability for longitudinal tracking in a costefficient manner.

\section{Ultrasound}

Clinically, ultrasound has been applied as a diagnostic modality to assess a number of physiologic states in real time, utilizing intrinsic differences in tissue density or flow parameters to provide valuable information on anatomy, tissue properties, or perfusion. From a research perspective, quantitative ultrasound has been utilized to quantify damaged and diseased muscle in DMD and other neuromuscular disorders [77]. Through quantification of grayscale levels (GSL) or quantitative backscatter analysis (QBA), one is able to quantitate the state of health of muscle. GSL measures the acoustic impedance of different tissue types (muscle, lipid, fibrosis), through quantification of images generated allowing for tissue type distinguishing. QBA directly analyses the amplitudes of reflected ultrasound echoes without data manipulation by the machine's intrinsic software, allowing for easy comparison between different proprietary devices. Objectively, studies in DMD have utilized ultrasound to identify muscles with greater muscle lipid and fibrosis [78], worsened strength and function [79], and has demonstrated the ability to detect longitudinal changes in young and older boys with DMD [80, 81].

In cross-sectional analyses, quantitative US demonstrated a negative correlation to function $\left(r^{2}=-0.6, p=0.02\right)$ and strength $\left(r^{2}=-0.4, p=0.03\right)$ negative correlation to functional tests $[66,79]$. In several longitudinal studies, subclinical disease progression, and correlation to age, ambulatory status, functional grading, muscle strength, and motor ability was able to be appreciated [80, 81]. Quantitatively, in one longitudinal study over two years of boys with DMD, the mean echo intensity of several upper extremity muscle groups increased over 2 years (regression coefficient $=0.49-0.64, p<0.05$ ), indicating progression of disease within the muscle [81]. Advantages of quantitative ultrasound include its ease of use, cost accessibility, outpatient access, ability to be used without sedation, and compliance in individuals who may be unable to lay still or flat because of contractures secondary to DMD disease processes for prolonged MR imaging or functional tests. Furthermore, similarly to MR and EIM, it can be used after boys lose ambulation, a major limitation of the 6MWT and other functional tests.

Though intra-user error and repeatability are concerns for ultrasound, data suggests feasibility and repeatability of using US in a longitudinal manner in human subjects [82]. As a matter of the nature of ultrasound, less data is able to be generated as compared to MR and EIM. GSL remains easier to analyze than QBA, though GSL is limited because it incorporates a lot of device-specific variables that modify the data as compared to QBA. As more correlative studies utilizing ultrasound for clinical trials are conducted, it is anticipated that a greater appreciation of quantitative ultrasound use will be generated.

\section{Measures Fit for Purpose}

Most importantly, one single biomarker or functional outcome measure may not be optimal for all clinical trials. To determine if a surrogate marker is fit-for-purpose, it must be able to sensitively detect change, be reliable, measure the welldefined concept of interest, and demonstrate clinically meaningful changes in measurements [83]. Though clinical trials ideally test a single variable or intervention, the DMD population is heterogeneous and frequently on a myriad of therapies, emphasizing the concept that studies are best served through a variety of measures, from measuring gross motor function to quantification of tissue pathophysiology. For instance, in some trials assessing bulk muscle growth, such as in trials of myostatin inhibition, MRI may be the optimal biomarker to accurately quantify changes cross-sectional area. However, in other trials that target sarcolemmal membrane stabilization, EIM may be the optimal biomarker, assessing restoration and stabilization of the sarcolemmal membrane. Though the cost of these non-invasive imaging systems may be initially higher than traditional measures, they are comparable or less than that of surgical biopsies requiring anesthesia and the comprehensive teams utilized for functional testing. Furthermore, by virtue of their sensitivity, data demonstrates the potential to reduce sample sizes and decrease clinical trial lengths, leading to more cost- and time-efficient clinical trials [83]. Overall, in an effort to match the pace of drug development, it is critical that non-invasive quantitative biomarkers are utilized in parallel comprehensive manners to reveal greater significant changes following therapeutic interventions.

\section{Conclusions}

As drug development has outpaced biomarker development, the outcome measures currently utilized in clinical trials for DMD can be optimized. The outcome measures discussed in 
this article - magnetic resonance imaging and spectroscopy, electrical impedance myography, and ultrasound-may reduce sample sizes and trial lengths, ultimately helping accelerate clinical trials. Though there has been increased interest in quantitative non-invasive biomarkers, their application is still in relative infancy when compared to the complexity of the biologics being tested in clinical trials. While the Food and Drug Administration currently does not recognize magnetic resonance imaging and spectroscopy, electrical impedance myography, or ultrasound as surrogate primary outcome measures for DMD, a growing body of literature supports the argument that such biomarkers may ultimately surpass currently accepted measures. With continued application of such biomarkers, it can be anticipated that they may ultimately become the mainstay of clinical trials in DMD.

Required Author Forms Disclosure forms provided by the authors are available with the online version of this article.

\section{EAppendix Supplement}

\section{Search terms}

Duchenne muscular dystrophymagnetic resonance imagingmagnetic resonance spectroscopyelectrical impedance myographyclinical trialsbiomarkersoutcome measures

\section{References}

1. Bushby K, Connor E. Clinical outcome measures for trials in Duchenne muscular dystrophy: report from International Working Group meetings. Clin. Investig. 2011;1:1217-1235.

2. Hoffman EP, Brown Jr. RH, Kunkel LM. Dystrophin: The protein product of the duchenne muscular dystrophy locus. Cell. 1987;51: 919-928.

3. Mah JK, Korngut L, Fiest KM, et al. A Systematic Review and Meta-analysis on the Epidemiology of the Muscular Dystrophies. Can. J. Neurol. Sci. J. Can. Sci. Neurol. 2016;43:163-177.

4. Birnkrant DJ, Bushby K, Bann CM, et al. Diagnosis and management of Duchenne muscular dystrophy, part 1: diagnosis, and neuromuscular, rehabilitation, endocrine, and gastrointestinal and nutritional management. Lancet Neurol. 2018;17:251-267.

5. Birnkrant DJ, Bushby K, Bann CM, et al. Diagnosis and management of Duchenne muscular dystrophy, part 2: respiratory, cardiac, bone health, and orthopaedic management. Lancet Neurol. 2018;17:347-361.

6. Birnkrant DJ, Bushby K, Bann CM, et al. Diagnosis and management of Duchenne muscular dystrophy, part 3: primary care, emergency management, psychosocial care, and transitions of care across the lifespan. Lancet Neurol. 2018;17:445-455.

7. Duchenne G-B. Physiologie des mouvements démontrée à l'aide de l'experimentation électrique et de l'observation clinique: et applicable à l'étude des paralysies et des déformations. Baillière; 1867.
8. Ervasti JM, Campbell KP. Membrane organization of the dystrophin-glycoprotein complex. Cell. 1991;66:1121-1131.

9. Sacco A, Mourkioti F, Tran R, et al. Short telomeres and stem cell exhaustion model Duchenne muscular dystrophy in $\mathrm{mdx} / \mathrm{mTR}$ mice. Cell. 2010;143:1059-1071.

10. Tidball JG, Wehling-Henricks M. Macrophages promote muscle membrane repair and muscle fibre growth and regeneration during modified muscle loading in mice in vivo. J. Physiol. 2007;578:327336.

11. Lee T, Takeshima Y, Kusunoki N, et al. Differences in carrier frequency between mothers of Duchenne and Becker muscular dystrophy patients. J. Hum. Genet. 2014;59:46-50.

12. McNally EM, Kaltman JR, Benson DW, et al. Contemporary Cardiac Issues in Duchenne Muscular Dystrophy. Circulation. 2015;131:1590-1598.

13. Melacini P, Vianello A, Villanova C, et al. Cardiac and respiratory involvement in advanced stage Duchenne muscular dystrophy. Neuromuscul. Disord. NMD. 1996;6:367-376.

14. Fayssoil A, Ogna A, Chaffaut C, et al. Natural history of cardiac function in Duchenne and Becker muscular dystrophies on home mechanical ventilation. Medicine (Baltimore). 2018;97:e11381.

15. Okubo M, Minami N, Goto K, et al. Genetic diagnosis of Duchenne/Becker muscular dystrophy using next-generation sequencing: validation analysis of DMD mutations. J. Hum. Genet. 2016;61:483-489.

16. Fenichel GM, Florence JM, Pestronk A, et al. Long-term benefit from prednisone therapy in Duchenne muscular dystrophy. Neurology. 1991;41:1874-1877.

17. Mendell JR, Moxley RT, Griggs RC, et al. Randomized, doubleblind six-month trial of prednisone in Duchenne's muscular dystrophy. N. Engl. J. Med. 1989;320:1592-1597.

18. Lebel DE, Corston JA, McAdam LC, et al. Glucocorticoid treatment for the prevention of scoliosis in children with Duchenne muscular dystrophy: long-term follow-up. J. Bone Joint Surg. Am. 2013;95:1057-1061.

19. Kinnett K, Noritz G. The PJ Nicholoff Steroid Protocol for Duchenne and Becker Muscular Dystrophy and Adrenal Suppression. PLoS Curr. 2017;9.

20. Eagle M, Baudouin SV, Chandler C, et al. Survival in Duchenne muscular dystrophy: improvements in life expectancy since 1967 and the impact of home nocturnal ventilation. Neuromuscul. Disord. NMD. 2002;12:926-929.

21. McDonald CM, Campbell C, Torricelli RE, et al. Ataluren in patients with nonsense mutation Duchenne muscular dystrophy (ACT DMD): a multicentre, randomised, double-blind, placebo-controlled, phase 3 trial. Lancet Lond. Engl. 2017;390:1489-1498.

22. Bushby K, Finkel R, Wong B, et al. Ataluren treatment of patients with nonsense mutation dystrophinopathy. Muscle Nerve. 2014;50: 477-487.

23. Mendell JR, Goemans N, Lowes LP, et al. Longitudinal effect of eteplirsen versus historical control on ambulation in Duchenne muscular dystrophy. Ann. Neurol. 2016;79:257-271.

24. Syed YY. Eteplirsen: First Global Approval. Drugs. 2016;76:16991704.

25. Goemans NM, Tulinius M, van den Hauwe M, et al. Long-Term Efficacy, Safety, and Pharmacokinetics of Drisapersen in Duchenne Muscular Dystrophy: Results from an Open-Label Extension Study. PLoS ONE [Internet]. 2016;11. Available from: https:// www.ncbi.nlm.nih.gov/pmc/articles/PMC5010191/.

26. Ricotti V, Spinty S, Roper H, et al. Safety, Tolerability, and Pharmacokinetics of SMT C1100, a 2-Arylbenzoxazole Utrophin Modulator, following Single- and Multiple-Dose Administration to Pediatric Patients with Duchenne Muscular Dystrophy. PLoS ONE [Internet]. 2016;11. Available from: https://www.ncbi.nlm.nih. gov/pmc/articles/PMC4824384/. 
27. Mazzone E, Vasco G, Sormani MP, et al. Functional changes in Duchenne muscular dystrophy: a 12-month longitudinal cohort study. Neurology. 2011;77:250-256.

28. Fleming TR, Powers JH. Biomarkers and surrogate endpoints in clinical trials. Stat. Med. 2012;31:2973-2984.

29. US Department of Health and Human Services Food and Drug Administration Center for Drug Evaluation and Research (CDER). Guidance for Industry and FDA Staff: Qualification Process for Drug Development Tools. 2014.

30. Katz R. Biomarkers and Surrogate Markers: An FDA Perspective. NeuroRx. 2004;1:189-195.

31. Hamuro L, Chan P, Tirucherai G, et al. Developing a Natural History Progression Model for Duchenne Muscular Dystrophy Using the Six-Minute Walk Test. CPT Pharmacomet. Syst. Pharmacol. 2017;6:596-603.

32. Bohannon RW, Bubela D, Magasi S, et al. Comparison of walking performance over the first 2 minutes and the full 6 minutes of the Six-Minute Walk Test. BMC Res. Notes. 2014;7:269.

33. Goemans N, Vanden Hauwe M, Signorovitch J, et al. Individualized Prediction of Changes in 6-Minute Walk Distance for Patients with Duchenne Muscular Dystrophy. PloS One. 2016;11:e0164684.

34. Pane M, Mazzone ES, Sivo S, et al. Long term natural history data in ambulant boys with Duchenne muscular dystrophy: 36-month changes. PloS One. 2014;9:e108205.

35. Chrzanowski SM, Baligand C, Willcocks RJ, et al. Multi-slice MRI reveals heterogeneity in disease distribution along the length of muscle in Duchenne muscular dystrophy. Acta Myol. Myopathies Cardiomyopathies Off. J. Mediterr. Soc. Myol. 2017;36:151-162.

36. Cacchiarelli D, Legnini I, Martone J, et al. miRNAs as serum biomarkers for Duchenne muscular dystrophy. EMBO Mol. Med. 2011;3:258-265.

37. Arpan I, Forbes SC, Lott DJ, et al. $\mathrm{T}_{2}$ mapping provides multiple approaches for the characterization of muscle involvement in neuromuscular diseases: a cross-sectional study of lower leg muscles in 5-15-year-old boys with Duchenne muscular dystrophy. NMR Biomed. 2013;26:320-328.

38. Arpan I, Willcocks RJ, Forbes SC, et al. Examination of effects of corticosteroids on skeletal muscles of boys with DMD using MRI and MRS. Neurology. 2014;83:974-980.

39. Carlier PG, Mercuri E, Straub V. Applications of MRI in muscle diseases. Neuromuscul. Disord. NMD. 2012;22 Suppl 2:S41.

40. Wary C, Azzabou N, Giraudeau C, et al. Quantitative NMRI and NMRS identify augmented disease progression after loss of ambulation in forearms of boys with Duchenne muscular dystrophy. NMR Biomed. 2015;28:1150-1162.

41. Hogrel J-Y, Wary C, Moraux A, et al. Longitudinal functional and NMR assessment of upper limbs in Duchenne muscular dystrophy. Neurology. 2016;86:1022-1030.

42. Forbes SC, Willcocks RJ, Triplett WT, et al. Magnetic Resonance Imaging and Spectroscopy Assessment of Lower Extremity Skeletal Muscles in Boys with Duchenne Muscular Dystrophy: A Multicenter Cross Sectional Study. PLoS ONE. 2014;9:e106435.

43. Mathur S, Lott DJ, Senesac C, et al. Age-related differences in lower-limb muscle cross-sectional area and torque production in boys with Duchenne muscular dystrophy. Arch. Phys. Med. Rehabil. 2010;91:1051-1058

44. Mercuri E, Talim B, Moghadaszadeh B, et al. Clinical and imaging findings in six cases of congenital muscular dystrophy with rigid spine syndrome linked to chromosome 1p (RSMD1). Neuromuscul. Disord. 2002;12:631-638.

45. Burakiewicz J, Sinclair CDJ, Fischer D, et al. Quantifying fat replacement of muscle by quantitative MRI in muscular dystrophy. J. Neurol. 2017;264:2053-2067.
46. Hooijmans MT, Niks EH, Burakiewicz J, et al. Non-uniform muscle fat replacement along the proximodistal axis in Duchenne muscular dystrophy. Neuromuscul. Disord. NMD. 2017;27:458-464.

47. Fischmann A, Hafner P, Gloor M, et al. Quantitative MRI and loss of free ambulation in Duchenne muscular dystrophy. J. Neurol. 2013;260:969-974.

48. Forbes SC, Walter GA, Rooney WD, et al. Skeletal muscles of ambulant children with Duchenne muscular dystrophy: validation of multicenter study of evaluation with MR imaging and MR spectroscopy. Radiology. 2013;269:198-207.

49. Gaeta M, Messina S, Mileto A, et al. Muscle fat-fraction and mapping in Duchenne muscular dystrophy: evaluation of disease distribution and correlation with clinical assessments. Preliminary experience. Skeletal Radiol. 2012;41:955-961.

50. Willcocks RJ, Triplett WT, Forbes SC, et al. Magnetic resonance imaging of the proximal upper extremity musculature in boys with Duchenne muscular dystrophy. J. Neurol. 2017;264:64-71.

51. Wokke BH, Bos C, Reijnierse M, et al. Comparison of dixon and T1-weighted MR methods to assess the degree of fat infiltration in duchenne muscular dystrophy patients. J. Magn. Reson. Imaging. 2013;38:619-624.

52. Wren TAL, Bluml S, Tseng-Ong L, et al. Three-point technique of fat quantification of muscle tissue as a marker of disease progression in Duchenne muscular dystrophy: preliminary study. AJR Am. J. Roentgenol. 2008;190:W8-12.

53. Hooijmans MT, Doorenweerd N, Baligand C, et al. Spatially localized phosphorous metabolism of skeletal muscle in Duchenne muscular dystrophy patients: 24-month follow-up. PloS One. 2017;12: e0182086.

54. Davies RC, Eston RG, Fulford J, et al. Muscle damage alters the metabolic response to dynamic exercise in humans: a 31P-MRS study. J. Appl. Physiol. 2011;111:782-790.

55. Lodi R, Muntoni F, Taylor J, et al. Correlative MR imaging and 31P-MR spectroscopy study in sarcoglycan deficient limb girdle muscular dystrophy. Neuromuscul. Disord. 1997;7:505-511.

56. Lott DJ, Forbes SC, Mathur S, et al. Assessment of intramuscular lipid and metabolites of the lower leg using magnetic resonance spectroscopy in boys with Duchenne muscular dystrophy. Neuromuscul. Disord. 2014;24:574-582.

57. Willcocks RJ, Arpan IA, Forbes SC, et al. Longitudinal measurements of MRI-T2 in boys with Duchenne muscular dystrophy: Effects of age and disease progression. Neuromuscul. Disord. 2014;24:393-401.

58. Kim HK, Laor T, Horn PS, et al. T2 Mapping in Duchenne Muscular Dystrophy: Distribution of Disease Activity and Correlation with Clinical Assessments1. Radiology. 2010;255: 899-908.

59. Mankodi A, Azzabou N, Bulea T, et al. Skeletal muscle water T2as a biomarker of disease status and exercise effects in patients with Duchenne muscular dystrophy. Neuromuscul. Disord. NMD. 2017;27:705-714.

60. Bishop CA, Ricotti V, Sinclair CDJ, et al. Semi-Automated Analysis of Diaphragmatic Motion with Dynamic Magnetic Resonance Imaging in Healthy Controls and Non-Ambulant Subjects with Duchenne Muscular Dystrophy. Front. Neurol. 2018;9:9.

61. Barnard AM, Willcocks RJ, Finanger EL, et al. Skeletal muscle magnetic resonance biomarkers correlate with function and sentinel events in Duchenne muscular dystrophy. PloS One. 2018;13: e0194283.

62. Willcocks RJ, Rooney WD, Triplett WT, et al. Multicenter prospective longitudinal study of magnetic resonance biomarkers in a large duchenne muscular dystrophy cohort. Ann. Neurol. 2016;79:535547. 
63. Bonati U, Hafner P, Schädelin S, et al. Quantitative muscle MRI: A powerful surrogate outcome measure in Duchenne muscular dystrophy. Neuromuscul. Disord. NMD. 2015;25:679-685.

64. Rutkove SB, Darras BT. Electrical impedance myography for the assessment of children with muscular dystrophy: a preliminary study. J. Phys. Conf. Ser. 2013;434.

65. Rutkove SB, Kapur K, Zaidman CM, et al. Electrical impedance myography for assessment of Duchenne muscular dystrophy. Ann. Neurol. 2017;81:622-632.

66. Rutkove SB, Geisbush TR, Mijailovic A, et al. Cross-sectional Evaluation of Electrical Impedance Myography and Quantitative Ultrasound for the Assessment of Duchenne Muscular Dystrophy in a Clinical Trial Setting. Pediatr. Neurol. 2014;51:88-92.

67. Zaidman CM, Wang LL, Connolly AM, et al. Electrical impedance myography in Duchenne muscular dystrophy and healthy controls: A multicenter study of reliability and validity. Muscle Nerve. 2015;52:592-597.

68. Rutkove SB, Shefner JM, Gregas M, et al. Characterizing Spinal Muscular Atrophy with Electrical Impedance Myography. Muscle Nerve. 2010;42:915-921.

69. Kolb SJ, Coffey CS, Yankey JW, et al. Baseline results of the NeuroNEXT spinal muscular atrophy infant biomarker study. Ann. Clin. Transl. Neurol. 2016;3:132-145.

70. Rutkove SB, Esper GJ, Lee KS, et al. Electrical impedance myography in the detection of radiculopathy. Muscle Nerve. 2005;32:335-341.

71. Statland JM, Heatwole C, Eichinger K, et al. Electrical impedance myography in facioscapulohumeral muscular dystrophy. Muscle Nerve. 2016;54:696-701.

72. Rutkove SB, Aaron R, Shiffman CA. Localized bioimpedance analysis in the evaluation of neuromuscular disease. Muscle Nerve. 2002;25:390-397.

73. Rutkove SB, Caress JB, Cartwright MS, et al. Electrical impedance myography as a biomarker to assess ALS progression. Amyotroph. Lateral Scler. 2012;13:439-445.
74. Rutkove SB, Zhang H, Schoenfeld DA, et al. Electrical impedance myography to assess outcome in amyotrophic lateral sclerosis clinical trials. Clin. Neurophysiol. 2007;118:2413-2418.

75. Shefner JM, Rutkove SB, Caress JB, et al. Reducing sample size requirements for future ALS clinical trials with a dedicated electrical impedance myography system. Amyotroph. Lateral Scler. Front. Degener. 2018;1-7.

76. Rodriguez S, Ollmar S, Waqar M, et al. A Batteryless Sensor ASIC for Implantable Bio-Impedance Applications. IEEE Trans. Biomed. Circuits Syst. 2016;10:533-544.

77. Pillen S, Arts IMP, Zwarts MJ. Muscle ultrasound in neuromuscular disorders. Muscle Nerve. 2008;37:679-693.

78. Heckmatt JZ, Dubowitz V, Leeman S. Detection of pathological change in dystrophic muscle with B-scan ultrasound imaging. Lancet Lond. Engl. 1980;1:1389-1390.

79. Zaidman CM, Connolly AM, Malkus EC, et al. Quantitative ultrasound using backscatter analysis in Duchenne and Becker muscular dystrophy. Neuromuscul. Disord. NMD. 2010;20:805-809.

80. Zaidman CM, Malkus EC, Connolly AM. Muscle ultrasound quantifies disease progression over time in infants and young boys with duchenne muscular dystrophy. Muscle Nerve. 2015;52:334-338.

81. Jansen M, van Alfen N, Nijhuis van der Sanden MWG, et al. Quantitative muscle ultrasound is a promising longitudinal follow-up tool in Duchenne muscular dystrophy. Neuromuscul. Disord. NMD. 2012;22:306-317.

82. Baumer TG, Davis L, Dischler J, et al. Shear wave elastography of the supraspinatus muscle and tendon: Repeatability and preliminary findings. J. Biomech. 2017;53:201-204.

83. Food and Drug Administration C for DE and. Development \& Approval Process (Drugs) - Drug Development Tools: Fit-forPurpose Initiative [Internet]. [cited 2019 Mar 3]. Available from: https://www.fda.gov/drugs/developmentapprovalprocess/ ucm505485.htm.

Publisher's Note Springer Nature remains neutral with regard to jurisdictional claims in published maps and institutional affiliations. 